\title{
THEORETICAL APPROACH IN SPORT PEDAGOGY AND USAGE OF COMMUNICATION
}

\author{
Aleksandra PEROVIC ${ }^{1}$, Ivana PARCINA ${ }^{2}$, Esmira KANALIC ${ }^{3}$ \\ ${ }^{1}$ Fakultet za menadžment u sportu, Alfa Univerzitet, Beograd, Srbija \\ ${ }^{3}$ SaTCIP Ltd. Vrnjačka Banja, Serbia
}

\begin{abstract}
Communication in everyday life is very important in interpersonal relationships. The level of understanding among the actors is directly conditioned by the type and quality of the communication itself. One of the subjects of this work is related to the use of verbal and nonverbal communication in sport. This form of communication is evident both in training and on the sports competitions. Sport psychology is the youngest discipline in the system of pedagogical sciences and one of the youngest disciplines in the system of sciences in sport. The study of theoretical issues of this discipline aims to determine the legality of upbringing and education in sport. In this paper we analyzed the interdependence of verbal communication with the psychology of sport are different and prominent possibilities of application of sport pedagogy.
\end{abstract}

\section{INTRODUCTION}

CPORT psychology is a psychological discipline that $\checkmark$ studies the behavior of people in various forms of sports activities. This is, without doubt, the shortest and clearest definition of sports psychology. However, this clarity is only apparent and hides the trap of imprecision, even incomplete because a proper understanding largely left. Communication is the process of sending and receiving information. It can be directed toward itself except what is directed towards the environment. Especially communication through words or verbal communication is what defines mankind. Research shows that communication is made up of words, voice, tone and nonverbal signals. It comes to the conclusion that it is much more important the way in which something is said, than what is said. The word communication means to do something general or common. In terms of whether it is achieved with itself or the environment, communication can be intrapersonal and interpersonal

\section{ASPECTS OF SPORTS PSYCHOLOGY STUDIES}

Psychology of sport can be divided into two large groups. The first group of problems are those that relate to understanding how psychological factors influence physical activity, or performance of individuals. The second group of problems we classify those related to the understanding of how participation in sports if physical activity in general affects the mental development and the personality of the person as a whole. In Fig. 1 are graphically presented techniques and coaching concepts.

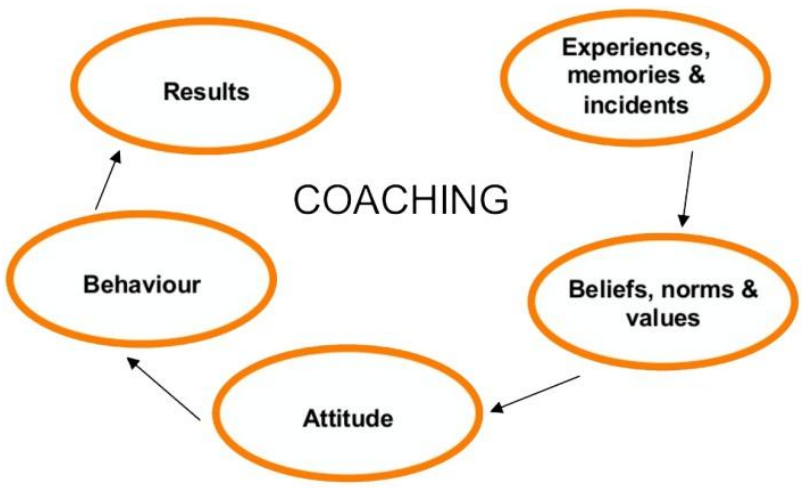

Fig. 1. Techniques and coaching concepts

Personality and Sports - What is the relationship between personality and sport? Although it has not reached general agreement in response to this question, it is possible to single out at least three directions of thought in this regard.

Emotional (in) stability and Sports - Emotional control is the relatively permanent ability of personality to the environment is evident emotion incentives that are in line with the power of incentives, and emotional stability, very similar to the composure of persons in dangerous or unexpected or stressful situations.

Anxiety and sport - Symptoms of anxiety becomes evident when their intensity far above the optimal, when disturb our activities, whether through increased perspiration, tremors, rapid breathing or, in turn, irritability or aggression. Being aware of these changes, there is also fear.

Domination, aggression and Sports - People who are successful in sports activities show a greater degree for domination which includes the pursuit of proving, a tendency to be too competitive, self-affirmation, etc.

Ability and Sports - In an attempt of systematization 
capabilities, it is possible to distinguish at least three types of abilities (more precisely: relatively separate segments abilities since they can not be clearly separated), which are sensory, psychomotor and intellectual capabilities [1].

\section{VERBAL AND NONVERBAL COMMUNICATION IN SPORT}

Verbal and non-verbal communication are essentially inseparable. They should be viewed as a whole, no matter how it was complex and complicated. "It is believed that reading the verbal text is a bouncy reading, while all communication that contains and allows nonverbal aspects and ongoing, simultaneous reading nonverbal content" [2].

Verbal or oral and written communication is the most common way to transmit information, news or messages in everyday life. Regardless of which method performs the main tool is language. Language enables man to express his thoughts, to transmit their experiences and to participate in social communication. Verbal communication involves at least two participants speakers and interlocutors. It should include: a clear objective, organization, efficiency, selectivity, building trust, control and performance.

Nonverbal communication is the process of transmitting and receiving characters that have a specific meaning. Something can become a sign, only if it has meaning for both sender and receiver. It is necessary to pay attention to certain things:

1) The fact that something is a sign does not indicate its meaning. It is necessary to know the relationship between the sign and its meaning.

2) The same character can have different meanings in different places or at different times. What would it mean to have to learn the rules of a particular use of the sign?

3) One same sign may mean different things to different people.

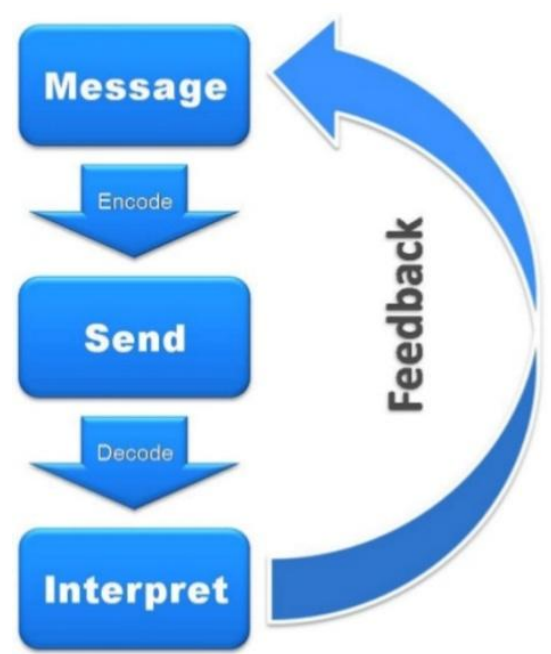

Fig 2. Process of effective communication
In Fig. 2 is shown the process of an effective communication which is the process of sending a message in such a way that the message received is as close in meaning as possible to the message intended. The specific form of nonverbal communication is particularly evident in the sport. The first and most important thing in sport is communication, both in the relationship between coaches and athletes, as well as mutual respect between the athletes themselves. Without good communication there is no good results, ie. there is no good success. All knowledge and experience that the coach wants to convey to the athletes is impossible without good communication skills you must possess.

It is believed that around $75 \%$ of communication between people, makes non-verbal communication and that is particularly noticeable in sports, because during the competition manager who is outside the field can only not-verbally communicate to the athlete on what he wants from him at that moment. Nonverbal communication is more easily transmitted and messages between referees and players, as well as messages between the players themselves during the game. [3] Non-verbal communication is carried out through a number of aspects of the so-called communication channels and sports are the most and the most important forms of nonverbal communication:

Visual communications (are related not only to watch and eye contact, but also the vision of accessible and useful social cues), facial expressions (reveal our emotions like happiness, sadness, fear, anger, surprise, disgust.), body (applies to signs of contact, posture, body orientation, gestures and nod).

Fig. 3 shows effective states of non-verbal communication.

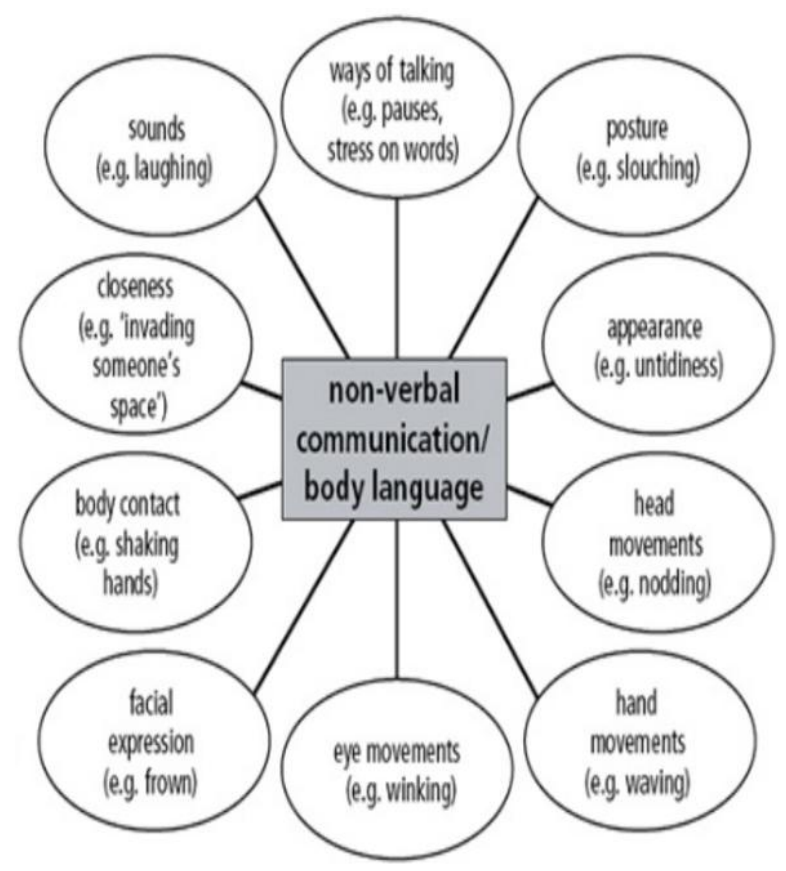

Fig. 3. Effective states of non-verbal communication 
In sports and in particular non-verbal communication is not always good, nor successful. Non-verbal communication during the competition can certainly be unsuccessful, this happens if the coach during the competition shouts, yells at the referee, waving his arms and so tries to explain his ideas athletes, it would only be needed several real hand movements so that the coach and athlete understand each other far better.

In sports, as in life, it is impossible not to communicate. In everything that is said or not, the tone of voice, speed of speech, the attitude of body, all the movements are always communicating. When the coach intentionally or unintentionally ignores the athlete he also performs communication [4]. This means that the words used in conversations are covering only 10 percent of the real meaning of communication, and the true meaning of words is just nonverbal component that is often completely unaware.

\section{ROLE OF SOME OF MOTIVES FOR SPORTS PERFORMANCE}

All those motives come to the fore in relations with other people we acquire by socialization. Likewise, it is difficult to imagine dealing with different sports activities without social motives, and success in them is almost impossible without the same. Therefore we also divide social motives that seem appropriate for presentation and application in sports psychology. On Fig. 3 are shown types of changes for different motivational factors.

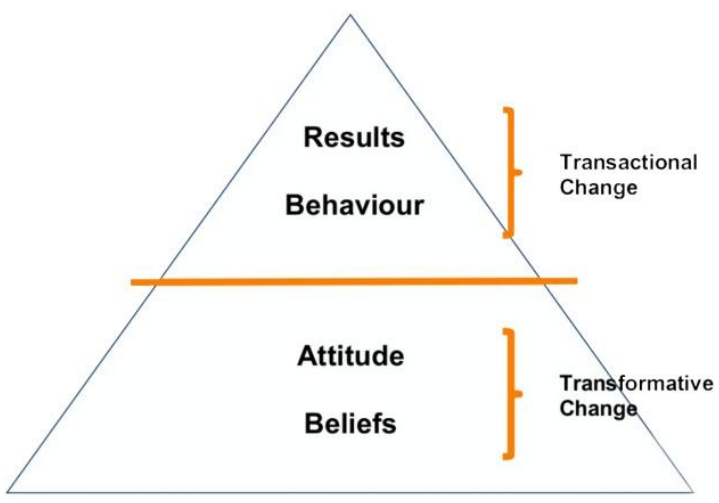

Fig. 3. Beliefs, norms and values in motivation

The social motives can be divided into two major groups [5]:

1) social motives that are focused on providing personal existence and afirmation which involve motive for achievement, motivation for recognition, status and prestige, the motive for the acquisition, motive power, and the motive for self-affirmation, and selfactualization, and so on and

2) social themes relating to association with other people, and involving gregarine motive, a motive for affective attachment, depending on the motive, and so on.
The motive for achievement and sport - The motive for achievement is usually defined as people striving to achieve a certain goal and the time he stands out from the others.

As follows from the above definitions for achievement, is a complex motif which consists of more simple, prominent among them being the motive militancy, the need for prestige and respect, level of aspiration, etc. [6]. The question is how to develop motivation for achievement in athletes and all other participants in sporting activities? Here we list just a few of the possibilities:

1) from an early age the child is necessary to pay attention to the emotional reward, any progress that show each step forward in its efforts to master a skill or knowledge;

2) Special attention should be given to those activities where the child is achieving success necessary to make an effort in relation to those affected owing to the possession of appropriate skills;

3) Always put inflict slightly more difficult tasks than those currently with ease can perform;

4) Do not do the work for the child, but rather to teach him to be independent (even if initially awkward or unsuccessfully, they will learn more through independent work than constant tutoring.);

5) The ultimate goal is necessary to explain milestone goals through the implementation of which the child is motivated to continue activities;

6) use a variety of ways on the way to achieving goals in order to prevent the occurrence of monotony and saturation in the work. Regardless of the activity being performed, there is a possibility that at least the conditions, if not the activity itself, can be made different and interesting [7].

Psychological preparation and sports - We can talk about the differences in the perception of the term psychological preparation of athletes depending on whether it is on top or on amateur sport. Differences in the understanding of the term exist and they depend on the approach of the author. If we ignore these differences stemming from the perception of the coverage, and not the substance of the term, there is the consent of the authors in this area on the following essential items of psychological preparation:

1) psychological preparation of athletes is longterm, continuous process;

2) carried out during the entire process of practicing sport (eg, in the training phase, not only in relation to the competition);

3) includes a planned and systematic activities of the athletes, coaches and professional associates (psychologists or doctors);

4) these activities are psychological, 
pedagogical and cognitive in nature; - are aimed at creating favorable conditions for the development of the disposition of personalities in general, as well as those specific, related to success in sport.

General psychological preparation for the lengthy process of exercise - psychological preparation of athletes at this stage refers to the introduction and development of all personality traits that studies the psychology of sport in general and on which insists, based on their importance for the success of the undertaken sport activities. Upon acceptance of this first and basic step in the psychological preparation, we make an assessment of specific properties such as, for example, the level of aspiration of the particular player or his motivation for training in specific terms for the specific competition, etc.

The key activities of the psychological preparation of athletes for the lengthy process of practice include:

1) developing those personality traits that predispose athletes to success and that, later, differ significantly from the others, such as perseverance, responsibility, self-control, emotional stability, self-confidence, determination, and so on.

2) developing motives that are important for success in sport, such as motive for achievement, level of aspiration and, in general, all those motives which, in the judgment of the coach or the players key incentives for him to personally train and be committed. For these reasons it is important to have good understanding of each player in the team.

3) set the stage and end goals that also have motivational force;

4) developing positive attitudes and values, particularly on sport as a chance that a person affirms, actualize, makes income, etc. [8].

In addition to the above, at this stage of psychological preparation, it is essential that coaches pay more attention to nurturing the appropriate social climate in the team, and develop a sense of belonging (that particular team) for each player, which itself leads to better results. Although extremely important for the success of the team in general, these activity trainers are very important in the work of teams that bring together only occasionally, as is the case with the right teams.

An important incentive is a trainer and a personal example: if he has satisfactory relationship with all the players, if there is no favorite, if he consistently praise or criticize all players depending on their behavior and performance, not by personal whim, etc., It creates the conditions ( and increases the likelihood) that the players will follow his example.

On the other hand, the training activities aimed at creating and maintaining group cohesion reflected in the increase frustration tolerance between players, reducing the intensity of anxiety or action of certain neurotic symptoms, all of which make psychological preparation for the lengthy process of exercise.

Psychological preparation for competition - This part of the psychological preparation guide activities of coaches and players to more specific issues in relation to the actual competitions or matches. Apart from dealing with their own needs before the competition, it is important to pay attention to the introduction of comparative characteristics of opponents. Taking into account the good and bad qualities the pass, we get an insight into the situation, so we can plan our own steps, or tactic, and when something becomes known, it reduces the feeling of insecurity. Personality of the trainer is key in these examples.

The coach must impose respect toward opponents by authority or power of his own personality, regardless of objective force of the opponents. Likewise, it is essential that the coach in advance takes some responsibility for the success or failure achieved, thus relieving the players and allowing them to really show their capabilities at the moment.

Bearing in mind that at this stage of psychological preparation is already done everything that could be done until then to develop a curriculum for the individual properties that are important for achieving success, players should brag and show off their strengths, thereby strengthening their self-confidence [9].

Psychological preparation for the actual competition This stage is characterized by supplementing the preparation with specific measures, contents and methods to the optimum level, in front of all the others already mentioned activities. However, work on the psychological preparation continues, or more precisely: does not stop. Psychological preparation after the competition is just as important after the experienced victory as after experiencing a failure or poor performance.

We are witnessing a situation in which the stars are formed from young players who have played a few notable games. Young people who are still in the process of maturing and learning about themselves and their own possibilities and desires, unprepared for life change on such a scale, thus lose their ground.

And in this case comes to the fore the psychological preparation after the competition [10]. Depending on whether they are undertaken by an athlete and a coach or requiring the participation of experts, we distinguish more specific method of psychological preparation of athletes. At first, those conducted by the coach or athlete we can classify them as following:

1) change to the content of thought (is achieved when reading a book or listening to music or watching a movie in which there is not much violence, in any case a choice of activity that acts relaxational at specific persons);

2) warming up (impact on reducing excitement or raising the level of activation, 
3) Massage and self-massage (used as a complement massage);

4) breathing exercises (reduces excitement, are carried out 3-4 times a day, although it is individual);

5) individually built a system of communication aimed at raising the activation (eg. It is great, go ahead, you're the best, etc.) Or calming (eg. Do not be afraid, it will be alright, etc.).

6) suggestive effect of coach (influence on increasing self-esteem).

The methods of psychological preparation that require engagement of professional persons include:

1) autogenous training (active suggestion and concentration);

2) progressive relaxation (alternately tightening and relaxing muscles to specific order);

3) Biofeedback training (includes meditation, exercise, yoga and transcendental meditation);

4) situational training (simulating conditions typical for the competition that lead to increased tension) and

5) intellectual or mental training (improving performance due to intense imagination of the performance, without actually performing simultaneous) [11].

All of these methods, regardless of whether it applied by the coach, athlete or psychologist, are aimed at reducing tension, stress and the elimination of psychosomatic disorders, and to create optimal conditions for achieving success in sports, and not just in sport. In addition to taking into account all of these specific proceedings psychological preparation, the results of psychological research shows that they are the most help athletes who were convinced it will help them.

\section{V.CONCLUSION}

Communication is a major driver of the development of mankind and cultural civilization. Many gestures of nonverbal communication are accepted in the region, with some the man is born. Non-verbal communication is much more important and complex aspect of interpersonal interaction than it at first appears. It happens everywhere and at any place. Internal motives are largely met by the activity launched by. External motives are satisfied with the outcome or the result of activities, so that those who are motivated by external important objective that can be achieved in this activity than the activity itself. Results of psychological research shows that people who are motivated to realize external engagement activity as something that is imposed, as a condition for the realization of the right objectives.

\section{REFERENCES}

[1] S. M. Balish, M. A. Eys, and A. I. Schulte-Hostedde, "Evolutionary sport and exercise psychology: Integrating proximate and ultimate explanations," Psychol. Sport Exerc., vol. 14, no. 3, pp. 413-422, May 2013.

[2] M. Cottingham, M. S. Carroll, D. Phillips, K. Karadakis, B. T. Gearity, and D. Drane, "Development and validation of the motivation scale for disability sport consumption," Sport Manag. Rev., vol. 17, no. 1, pp. 49-64, Feb. 2014.

[3] L. Dacica, "The Formative Role of Physical Education and Sports," Procedia - Soc. Behav. Sci., vol. 180, pp. 1242-1247, May 2015.

[4] S. A. M. Fenton, J. L. Duda, E. Quested, and T. Barrett, "Coach autonomy support predicts autonomous motivation and daily moderate-to-vigorous physical activity and sedentary time in youth sport participants," Psychol. Sport Exerc., vol. 15, no. 5, pp. 453-463, Sep. 2014

[5] A. LeUnes, Encyclopedia of Human Behavior. Elsevier, 2012.

[6] A. Maitland, L. A. Hills, and D. J. Rhind, "Organizational culture in sport - A systematic review," Sport Manag. Rev., vol. 18, no. 4, pp. 501-516, Jan. 2015

[7] L. Monacis, O. Estrada, M. Sinatra, G. Tanucci, and V. de Palo, "Self-determined Motivation, Sportspersonship, and Sport Orientation: A Mediational Analysis," Procedia - Soc. Behav. Sci., vol. 89, pp. 461-467, Oct. 2013.

[8] V. Morelli and C. Davis, "The potential role of sports psychology in the obesity epidemic.," Prim. Care, vol. 40, no. 2, pp. 507-23, Jun. 2013.

[9] E. Sherry, N. Schulenkorf, and L. Chalip, "Managing sport for social change: The state of play," Sport Manag. Rev., vol. 18, no. 1, pp. 1-5, Feb. 2015.

[10] J. L. Van Raalte, A. Vincent, and B. W. Brewer, "Self-talk: Review and sport-specific model," Psychol. Sport Exerc., vol. 22, pp. 139-148, Jan. 2016.

[11] M. R. Weiss and A. C. Phillips, International Encyclopedia of the Social \& Behavioral Sciences. Elsevier, 2015. 